\title{
Radiofrequency ablation of non-resectable lung tumors
}

\author{
Vaclav Simanek ${ }^{a}$, Jiri Kleckaa ${ }^{a}$ Vladislav Treska ${ }^{a}$, Kristyna Ohlidalovab ${ }^{b}$ Hynek Mirka ${ }^{b}$
}

\begin{abstract}
Background. Radiofrequency thermal ablation (RFA) is a minimally invasive, image guided technique for destroying tumour cells without damage to adjacent healthy tissue. It is used for partial or complete ablation of non resectable lung cancers and cancers of metastases to lung, providing an effective, relatively safe option for patients ineligible for surgery. We describe our experience with it.

Methods. In 2005 and 2006, we performed radiofrequency ablation of 7 lung lesions in 6 patients. RFA was done percutaneously under image guided CT scan in 5 patients and in one patient during thoracotomy when we found a radically unresectable tumor necessitating debulking. CT lung screening was performed after 6 months and PET/CT was done within 12 months.

Results. In the course of the screening, we diagnosed regression in 2 patients, a stationary state in 2 cases and local tumor progression in 2 patients, using computed tomography within 6 months after RFA. Using PET/CT within 12 months, we diagnosed non-ablation and liver metastases (there were none before) in one of the two patients with a stationary state diagnosed by means of CT before and recurrence of primary tumor in another patient. In one case of diagnosed regression, we diagnosed tumor progression. The patients survived an average of 30 months (range 9 to 60 months). Conclusion. RFA of lung tumors is an easy method with little patient discomfort. It can be performed percutaneously using guided CT under general anaesthesia. RFA of lung tumors possibly alone or in combination with oncology treatment can prolong patient life.
\end{abstract}

Key words: radiofrequency ablation, selective lung ventilation, lung CT scan, lung PET/CT

Received: March 28, 2012; Accepted with revision: July 19, 2012; Available online: September 5, 2012

http://dx.doi.org/10.5507/bp.2012.077

${ }^{a}$ Department of Surgery, University Hospital in Pilsen, Czech Republic

${ }^{b}$ Department of Imaging Methods, University Hospital in Pilsen

Corresponding author: Vaclav Simanek, e-mail: simanek@fnplzen.cz

\section{INTRODUCTION}

As long as 5000 years ago the ancient Egyptians were treating tumors with heat. The Greeks, from which the word hyperthermia comes, too, understod the effects of heat on tissue. In the past heat was especially used to stop bleeding and treat surface lesions. In 1891, the physicist d'Arsonval described the effects of alternating current penetrating tissue and warming it. The collagen structures were then dehydrated and degenerated without any pain or muscle contraction. In the year of 1908, Beer used the method of radiofrequency coagulation for the treatment of urinary bladder tumors and Clarek used the same for the destruction of skin tumors as well as cervix and breast. Further, radiofrequency coagulation is used for the treatment of foci of spontaneous activity in neurosurgery, for gastroenterology endoscopic surgery and for the treatment of dysrhythmia in cardiology. In the late 1980s, Rossi and McGraham capitalised on the neurosurgeons' experience and used radiofrequency coagulation for the destruction of primary liver tumors. Radiofrequency thermal ablation of lung tumors (RFA) was first performed in 1983. This destruction method uses the effects of alternating current in a frequency of $460 \mathrm{kHz}$ and a power of $50-200 \mathrm{~W}$ while a special probe is inserted into lung parenchyma. In the surroundings of the probe, there is ionic agitation and pulse temperature rises. At a temperature of about $50{ }^{\circ} \mathrm{C}$ there is spherical coagulation necrosis of lung tissue, including the tumor. Enzyme and structural changes of cells already occur at a temperature of $42^{\circ} \mathrm{C}$. Although the produced electrodes are used for the treatment of tumors of one to five centimeters, in the case of lung tissue, the best results are achieved in the coagulation of tumors of three centimeters. Non-ablation is a state when the complete coagulation necrosis of tissue is not achieved in the proximity of blood vessels as a consequence of cooling by the blood stream. The RFA probe can be inserted into lung parenchyma both per surgically (thoracotomy and thoracoscopy) and by computed tomography. Above all, percutaneous access is convenient for the patient, when local anaesthesia is used in conjunction with analgosedation $^{1,2}$.

\section{METHODS}

In 2005 and 2006, we performed radiofrequency ablation of seven lung lesions in six patients in the Department of Surgery of the University Hospital in Pilsen, the Czech Republic. Owing to tumor recurrence, there was a need to repeat RFA in one patient. RFA was performed percutaneously under image guided CT scan in five patients and in one patient during thoracotomy where we found a radically unresectable tumor requiring reduction of tumor 
mass (debulking). There were 4 men and 2 women, average age 61.6 (range 42-78) In three cases, we performed RFA of primary lung carcinoma. In one patient, there was a need for RFA of a metastasis of primary lung carcinoma after a previous second-side lung resection. In two cases, we performed RFA of a lung metastasis of colorectal carcinoma (Table 1). The average size of the tumor was $27 \mathrm{~mm}$ (range 13 to $45 \mathrm{~mm}$ ).

Table 1. Patients and lesion size.

\begin{tabular}{|c|c|c|c|}
\hline $\begin{array}{l}\text { Patient } \\
\text { No. }\end{array}$ & $\begin{array}{c}\text { Age } \\
\text { (years) }\end{array}$ & Type of tumor & $\begin{array}{l}\text { Tumor size } \\
\qquad(\mathrm{mm})\end{array}$ \\
\hline 1a & 78 & primary lung cancer & 31 \\
\hline $1 b$ & & $\begin{array}{l}\text { recurrence of primary } \\
\text { lung cancer }\end{array}$ & 42 \\
\hline 2 & 56 & primary lung cancer & 45 \\
\hline 3 & 55 & $\begin{array}{l}\text { metastasis of colorectal } \\
\text { carcinoma }\end{array}$ & 18 \\
\hline 4 & 74 & primary lung cancer & 26 \\
\hline 5 & 42 & $\begin{array}{l}\text { metastasis of colorectal } \\
\text { carcinoma }\end{array}$ & 13 \\
\hline 6 & 65 & $\begin{array}{l}\text { metastasis of primary } \\
\text { lung cancer }\end{array}$ & 17 \\
\hline
\end{tabular}

The combined thoracotomy surgery was performed in the operating theatre of the Department of Surgery of the University Hospital in Pilsen. The percutaneous surgeries using CT navigation were performed in the Department of Imaging Methods of the same hospital (Fig. 1). All surgeries were performed under all the rules and regulations for surgery in patients treated under general anaesthesia with selective intubation and limited ventilation of the operated lung wing. After aiming at the tumor in lung parenchyma, we inserted a conductor into the tumor and placed the RFA Needle over the conductor (Fig.2). After performing RFA of the tumor, we used computed tomography to determine the success of the surgery (the picture of opalescent glass) and to exclude complications (Fig. 3). After six hours, we used lung X-ray to evaluate the developing lung parenchyma. The CT lung screening was performed after six months and PET/CT was done within twelve months.

\section{RESULTS}

The most frequent complication of the lung surgery, which was pneumothorax, occurred in three patients and was discovered on lung X-ray. There was only one case where we performed chest drainage after thoracotomy. One patient developed pleuropneumonia with an exudate on the side of the performed percutaneous RFA on the sixth day after the surgery, which was resolved by antibiotics and doing a chest drainage. We noticed no other complications. After discharge, the patients were transferred

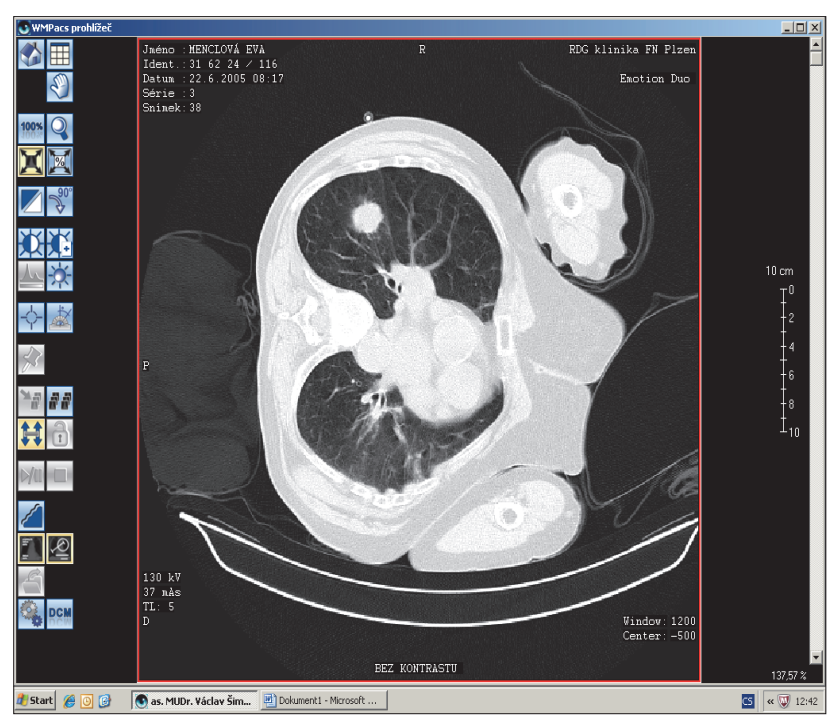

Fig. 1. CT scan - primary lung cancer in the lower lobe of right lung before RFA.

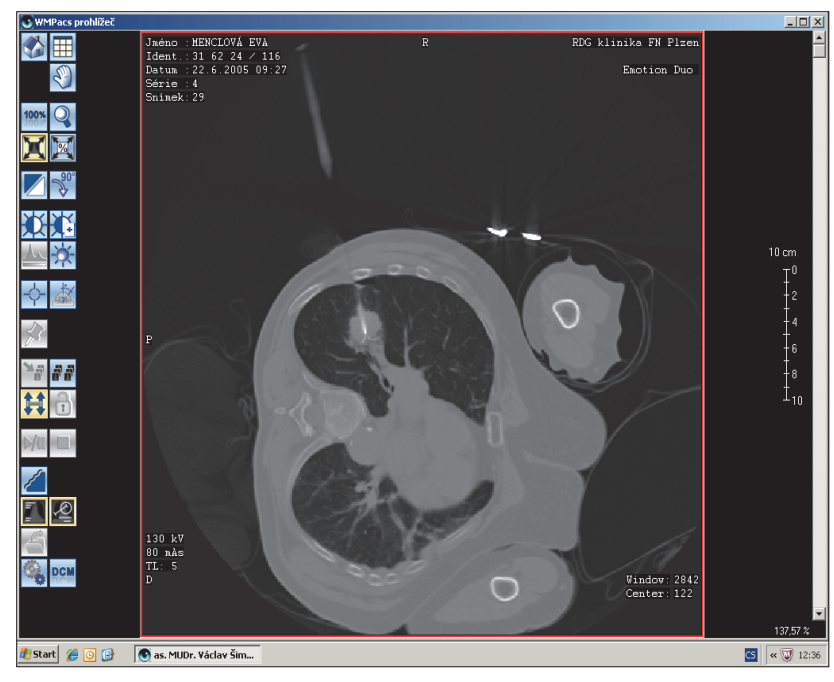

Fig. 2. CT scan - primary lung cancer after the introduction of RFA needle.

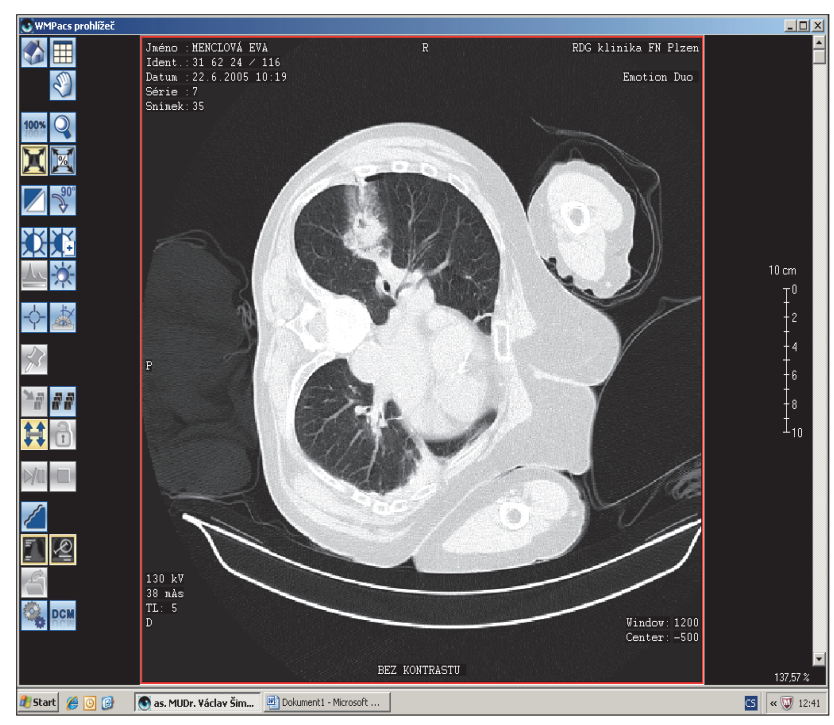

Fig. 3. CT scan after RFA - a picture of opalescent glass. 
to oncologists and underwent other oncology treatments (Table 2).

In the course monitoring the patients, we diagnosed regression in 2 patients, a stationary state in 2 cases and local tumor progression in 2 patients using computed tomography within 6 months after RFA. Using PET/CT within 12 months, we diagnosed non-ablation and liver metastases (there were none before) in one of two patients. The stationary state that had been diagnosed by means of CT before and there was recurrence of primary tumor in the other patient. In the case of the diagnosed progression, the PET/CT diagnosed extra-lung lesions as well. In one case of diagnosed regression, we could not use PET/CT, owing to previous complications of this examination. In one case, the PET/CAT scan was done within 18 months and we diagnosed tumor progression here as well (Fig. 4). The patients survived 30 months on average (range 9 to 60 months). In 5 cases, the cause of death was generalization of the basic cancer, and one patient died of cardiac failure within 42 months after the surgery (Table 3).

\section{DISCUSSION}

RFA of lung tumors is a method of choice in the case of patients who cannot be indicated for radical resection because of tumor localization or size and limited vital capacity if the lung parenchyma is afflicted with chronic disease. Further, it is used in the case of serious comorbidities which are a contraindication for thoracotomy or selective ventilation. In the case of a large unresectable tumors, RFA can be used palliatively for reducing tumor mass (debulking). The developing hyperthermic reaction

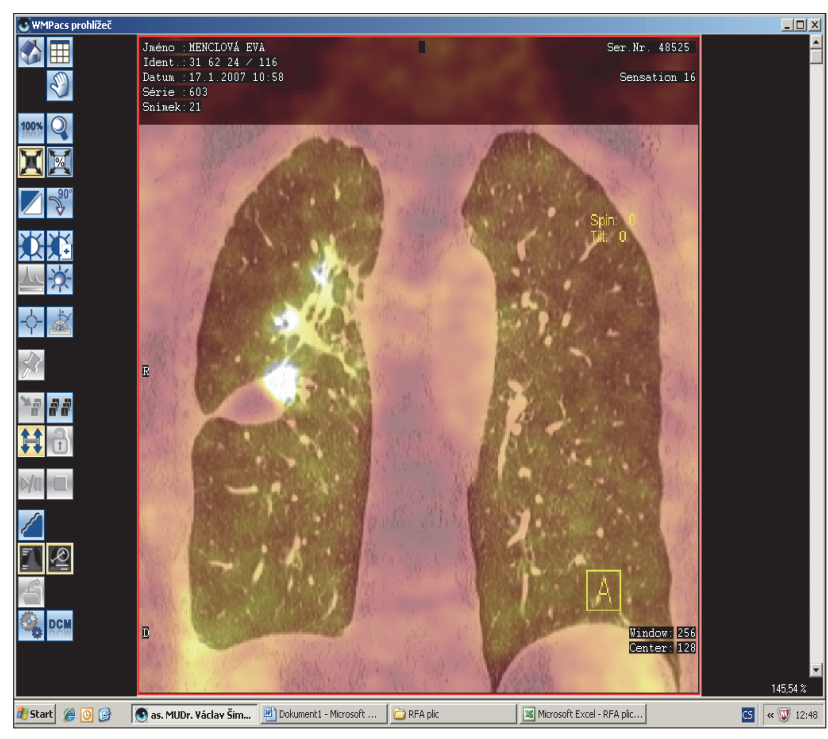

Fig. 4. PET/CT scan of the lung - 18 months after RFA primary lung cancer.

can even enhance the immune response. The reduction of tumor mass (cytoreduction) causes the production of tumor necrotizing factor with a local inflammatory response (HSP - heat shock protein). Heating the tumor increases tumor antigens, cell death improves the immune response and the heat increases the permeability of blood vessels in the tumor and adhesivity of leukocytes to endothelial cells ${ }^{3}$.

In the case of peripheral tumors, we use either wedgeshaped resection or laser metastasectomy while RFA is most suitable for tumors that are centrally located. It is these areas that are often unreachable by chemotherapy.

Table 2. Type of Surgery, Postoperative Lung X-Ray and Complications.

\begin{tabular}{cllcc}
\hline Patient & \multicolumn{1}{c}{ Summary } & Postoperative lung X-ray & Chest drainage & Complication \\
\hline 1a & percutaneous RFA & pneumothorax $5 \mathrm{~mm}$ & no & No \\
1b & percutaneous RFA & lungs developed & no & No \\
2 & thoracotomy + RFA & pneumothorax $10 \mathrm{~mm}$ & yes & No \\
3 & percutaneous RFA & lungs developed & no & No \\
4 & percutaneous RFA & lungs developed & no & No \\
5 & percutaneous RFA & pneumothorax $5 \mathrm{~mm}$ & yes & pleuropneumonia \\
6 & percutaneous RFA & lungs developed & no & No \\
\hline
\end{tabular}

Table 3. Results of CT and PET/CT after RFA.

\begin{tabular}{llll}
\hline Patient & Lung CT after 6 months & PET/CT within 12 months & Survival time (months) \\
\hline 1a & stationary diagnosis & recurrence near the site of destruction & 42 \\
$1 \mathrm{~b}$ & Progression & non-ablation and progression & \\
2 & Progression & generalization of pleura & 13 \\
3 & Progression & lung, liver, kidney and spinal column metastases & 9 \\
4 & Regression & Progression & 38 \\
5 & stationary diagnosis & liver non-ablation, liver metastases & 23 \\
6 & Regression & 0 & 60 \\
\hline
\end{tabular}


However there is a question of the protection of hill structures from heating effects of the RFA probe. It is also possible to indicate RFA in patients who refuse major surgery. Apart from this, there are also non-invasive methods that are safe and effective. Clinically proven non-invasive methods include stereotactic ablative radiotherapy (SABR). Treatment for early stage inoperable non-small cell lung cancer should be tailored to individual patients, and under certain circumstances, a combined approach may be beneficial ${ }^{4}$.

However, we cannot overlook the fact that RFA of lung, results in a larger number of non-ablations, too, which is pertinent especially to the treatment of lesions of over three centimeters (30\%): unlike liver tissue, the lung has higher impedance and this limits RFA efficacy. The histology results confirmed the persistence of malignant cells near bronchi. It is possible to use a cluster needle or a physiological solution in the surroundings of the tumor for greater efficacy of RFA. In our sample, we limited cooling of the needle by using selective lung ventilation, which made aiming at the lesion easier if RFA was performed in connection with CT ( ref. $^{5}$ ).

Although the most frequent complication is pneumotorax (from $20-40 \%$ ), there is a need to use chest drainage only in $10 \%$. The pleural exudate $(10-30 \%)$ is noticed during the treatment of surface lesions (less than one centimeter under pleura) and is spontaneously resorbed. Less frequent complications include haemoptysis (5-30\%), bronchopleural fistula, diaphragm paresis, continuing pains and subcutaneous emphysema ${ }^{6,7}$. Infections (2-5\%) are connected with the formation of a cavity after the successful ablation and occur in the case of a lung abscess or aspergillosis in immunocompromised patients ${ }^{8,9}$. Rare complications of percutaneous RFA of lung tumors, include injury to the ganglion stellatum ${ }^{10}$ or lesion of the brachial plexus ${ }^{11}$.

\section{CONCLUSION}

RFA of lung tumors is an easy technice involving minimum patient stress. It can be performed percutaneously using CT for guidance under general anaesthesia and analgosedation. Distinctly better results are achieved for lesions of less than three centimeters. The number of lesions of one lung lobe should not exceed five. The literature however, suggest that it is a palliative method and cannot be expected to replace radical resection. Our results show that it can prolong the patient's life by more than 24 months especially if used in connection with oncology treatment. Regarding the monitoring of treated foci we prefer PET/CT.

\section{ACKNOWLEDGEMENT}

The project was supported by the grant of the Ministry of Health, NS 9729-4/2008.

Authorship contributions: VS: manuscript writing; VS, JK: literature search; VS, KO, HM: data collection; VS, VT: data analysis and interpretation; VS, VT: final approval.

Conflict of interest statement: None declared.

\section{REFERENCES}

1. Skalicky T, Treska V. Radiofrequency ablation of liver tumors. Maxdorf 2006.

2. Mellot F, Friard S, Doubre H, Guth A, Chapelier A, Scherrer A, Couderc LJ. Radiofrequency treatment of lung tumours. Rev Pneumol Clin 2011;67(4):238-43.

3. Rao P, Escudier B, de Baere T. Spontaneous regression of multiple pulmonary metastases after radiofrequency ablation of a single metastasis. Cardiovasc Intervent Radiol 2011;34(2):424-30.

4. Bilal H, Mahmood S, Rajashenker B, Shah R. Is radiofrequency ablation more effective than stereotactic ablative radiotherapy in patients with early stage medically inoperable non-small lung cancer? Interact Cardiovasc Thorac Surg 2012 May 10. [Epub ahead of print] doi: 10.1093/icvts/ivs179

5. Hiraki T, Gobara H, Mimura H, Toyooka S, Fujiwara H, Yasui K, Sano Y, Iguchi T, Sakurai J, Tajiri N, Mukai T, Matsui Y, Kanazawa S. Radiofrequency ablation of lung cancer at Okayama University Hospital:a review of 10 years of experience. Acta Med Okayama 2011;65(5):287-97.

6. Ambrogi MC, Fanucchi O, Cioni R, Dini P, De Liperi A, Cappelli C, Davini F, Bartolozzi C, Mussi A. Long-term results of radiofrequency ablation treatment of stage I non-small cell lung cancer: a prospective intention-to-treat study. J Thorac Oncol 2011;6(12):2044-51.

7. Hiraki T, Gobara H, Shibamoto K, Mimura H, Soda Y, Uka M, Masaoka Y, Toyooka S, Kanazawa S. Technique for creation of arteficial pneumotorax fo pain relief during radiofrequency ablation of peripheral lung tumors:report of seven cases. J Vasc Interv Radiol 2011;22(4):503-6.

8. Kashima M, Yamakado K, Takaki H, Kodama H, Yamada T, Uraki J, Nakatsuka A. Complications after 1000 lung radiofrequency ablation sessions in 420 patients: single center's experiences. AJR Am Roentgenol 2011;197(4):W 576-80.

9. Nomori H, Imazu Y, Watanabe K, Ohtsuka T, Naruke T, Kobayashi T, Suemasu K. Radiofrequency ablation of pulmonary tumors and normal lung tissue in swine and rabbits. Chest2005;127(3):973-7.

10. Palussiére J, Cannella M, Gómez F, Ferron S, Descat E. Stellate ganglion Indry after percutaneous radiofrequency ablation of a lung tumor. Cardiovasc Intervent Radiol 2011;34(4):873-6.

11. Hiraki T, Gobara H, Mimura H, Sano Y, Toyooka S, Shibamoto K, Kishi $R$, Uka M, Kanazawa S. Brachial nerve injury caused by percutaneous radiofrequency ablation of apical lung cancer: a report of four cases. J Vasc Interv Radiol 2010;21(7):1129-33. 